\title{
BMJ Open Neighbouring green space and mortality in community-dwelling elderly Hong Kong Chinese: a cohort study
}

\author{
Dan Wang, ${ }^{1,2}$ Kevin Ka-Lun Lau, ${ }^{2,3,4}$ Ruby Yu, ${ }^{2,5}$ Samuel Y S Wong, ${ }^{1,6}$ \\ Timothy T Y Kwok, ${ }^{2,5}$ Jean Woo ${ }^{2,5}$
}

To cite: Wang D, Lau KK-L, Yu R, et al. Neighbouring green space and mortality in community-dwelling elderly Hong Kong Chinese: a cohort study. BMJ Open 2017;7:e015794. doi:10.1136/ bmjopen-2016-015794

- Prepublication history and additional material for this paper are available online. To view these files please visit the journal online (http://dx. doi. org/10.1136/bmjopen-2016015794).

Received 3 January 2017 Revised 7 June 2017

Accepted 13 June 2017

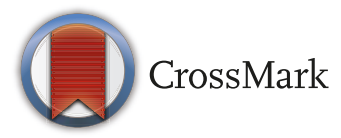

${ }^{1}$ The Jockey Club School of Public Health and Primary Care, The Chinese University of Hong Kong, Hong Kong, China ${ }^{2}$ CUHK Jockey Club Institute of Ageing, The Chinese University of Hong Kong, Hong Kong, China ${ }^{3}$ Institute of Future Cities, The Chinese University of Hong Kong, Hong Kong, China ${ }^{4}$ Institute of Environment, Energy and Sustainability, The Chinese University of Hong Kong, Hong Kong, China

${ }^{5}$ Department of Medicine and Therapeutics, The Chinese University of Hong Kong, Hong Kong, China

${ }^{6}$ Hong Kong Institute of Intergrative Medicine, The Chinese University of Hong Kong, Hong Kong, China

Correspondence to

Dr Jean Woo;

jeanwoowong@cuhk.edu.hk

\section{ABSTRACT}

Objective Green space has been shown to be beneficial for human wellness through multiple pathways. This study aimed to explore the contributions of neighbouring green space to cause-specific mortality.

Methods Data from 3544 Chinese men and women (aged $\geq 65$ years at baseline) in a community-based cohort study were analysed. Outcome measures, identified from the death registry, were death from all-cause, respiratory system disease, circulatory system disease. The quantity of green space (\%) within a $300 \mathrm{~m}$ radius buffer was calculated for each subject from a map created based on the Normalised Difference Vegetation Index. Cox proportional hazard models adjusted for demographics, socioeconomics, lifestyle, health conditions and housing type were used to estimate the HRs and $95 \%$ Cls.

Results During a mean of 10.3 years of follow-up, 795 deaths were identified. Our findings showed that a $10 \%$ increase in coverage of green space was significantly associated with a reduction in all-cause mortality (HR $0.963,95 \% \mathrm{Cl} 0.930$ to 0.998$)$, circulatory system-caused mortality (HR $0.887,95 \% \mathrm{Cl} 0.817$ to 0.963 ) and strokecaused mortality (HR $0.661,95 \% \mathrm{Cl} 0.524$ to 0.835 ), independent of age, sex, marital status, years lived in Hong Kong, education level, socioeconomic ladder, smoking, alcohol intake, diet quality, self-rated health and housing type. The inverse associations between coverage of green space with all-cause mortality (HR 0.964, 95\% Cl 0.931 to 0.999 ) and circulatory system disease-caused mortality (HR $0.888,95 \% \mathrm{Cl} 0.817$ to 0.964 ) were attenuated when the models were further adjusted for physical activity and cognitive function. The effects of green space on all-cause and circulatory system-caused mortality tended to be stronger in females than in males.

Conclusion Higher coverage of green space was associated with reduced risks of all-cause mortality, circulatory system-caused mortality and stroke-caused mortality in Chinese older people living in a highly urbanised city.

\section{INTRODUCTION}

The global population is experiencing a demographic transition towards an increase in ageing. While many studies have examined the impact of personal factors such as genetics, health behaviours and psychosocial elements, few studies have directly addressed

\section{Strengths and limitations of this study}

- This community-based longitudinal study explored the contributions of neighbouring green space on mortality in Chinese men and women aged 65 years and older living in a highly urbanised city, who are the most vulnerable to environmental stressors.

- This study measured the coverage of green space within the walking-reachable buffer for each subject, with strict recruiting criteria ensuring the relatively stable exposure (ie, coverage of green space).

- Apart from demographics, socioeconomics and lifestyle factors, self-rated health and housing type were controlled in the analysis, so that the precision in estimating the independent effect of green space was improved.

- The number of deaths from ischaemic heart diseases, acute myocardial infarction and stroke in the study was small. Further studies with a larger sample size and prospective design are warranted to confirm the beneficial effects of green space on health.

- The measurements of air quality and traffic noise may not be accurate. Further studies should adopt direct means of determining air pollution and noise level.

the impact of the living environment on wellness in the elderly, taking both health-related and neighbouring environment factors into account. Nevertheless, the living environment has gradually come to be recognised as a critical health determinant that contributes to multiple aspects of wellness. ${ }^{1}$ Green space, as an important constituent of the living environment, is defined as land which consists predominantly of unsealed, permeable, 'soft' surfaces such as trees, grass, plants and other natural vegetation, ${ }^{2}$ and has been shown to modify the micro-climate by absorbing solar radiation and air pollutants, enhancing air quality and buffering wind and noise. ${ }^{2-4}$ Green space can also provide residents with a visually and accessibly natural landscape. All of these potential benefits, directly as well 
as indirectly, protect the elderly from disproportionate decline in overall capacity on the course of getting older and also from the negative effects of a congested environment. ${ }^{56}$

The Global Age-Friendly Cities Project established in 2007 advocates providing a sustainable and age-friendly living environment in order to promote life quality of the elderly in a comprehensive and cost-effective way. ${ }^{7}$ Despite the fact that older people are biologically more vulnerable to environmental stressors as a result of declining physical function, frailty and mortality, ${ }^{89}$ the longer duration in the neighbouring environment and hence a wish to live in the same place as they getting older ${ }^{10}$ highlight the importance of estimating the health effect of neighbouring green space. In view of the fact that Hong Kong is one of the most densely populated yet also greenest cities in Asia, ${ }^{11}$ and since it currently has the longest life expectancy at birth in the world, ${ }^{12}$ studies assessing the impact of green space on the elderly citizen are critically important.

A cohort study conducted in Japan showed that green space can improve longevity among seniors and improve their capacity for independence. ${ }^{13}$ Other studies have suggested that green space is protective against all-cause mortality, ${ }^{13-15}$ cardiovascular and respiratory systemcaused mortality, ${ }^{4} 141617$ and self-perceived, long-term psychological well-being. ${ }^{18}{ }^{19}$ Studies also have reported that sufficient green space was specifically correlated with a decreased risk of cerebrovascular diseases, ${ }^{20}$ obesity, ${ }^{21}$ diabetes, ${ }^{22}$ osteoporosis and injuries caused by falls, ${ }^{23}$ as well as a higher likelihood of doing physical activity. ${ }^{24-26}$ However, most of these previous findings are based on ecological or cross-sectional design and among one-third of them, green space was not the primary factor being measured, so no conclusion regarding the independent effect of green space can be drawn. ${ }^{627}$ Few studies have convincingly measured the effect size of green space on mortality to date. ${ }^{13} 1428-30$

Using a community-based cohort of Chinese men and women aged 65 years and older who were followed up to 14 years, we aimed to explore the contributions of neighbouring green space to cause-specific mortality, with adjustments for a range of potential covariates, including demographics, socioeconomics, lifestyle, health conditions and environmental factors. We also aimed to determine if there are gender differences in the association.

\section{METHODS}

\section{Study design and subjects}

Since 2001, a community-based cohort of 4000 Chinese elderly aged 65 years and older residing in all regions of Hong Kong has been studied for predictors of fractures. Recruitment notices were placed in elderly community centres and housing estates and talks given explaining the proposal of the study; then, eligible elderly volunteers were invited to attend a health check at the School of Public Health, the Chinese University of Hong Kong. We excluded those who were unable to walk independently, had undergone bilateral hip replacement, were not competent to give informed consent or had medical conditions such as cancer, end-stage renal disease, heart disease or chronic lung disease, in which conditions were confirmed by the study doctors as a threat on short-term survival. Four thousand subjects at baseline were approximately equal in number in each of three age groups $(65-69,70-74,75+$ years $),{ }^{31} 32$ and were followed up for two rounds in 2003-2005 and 20052007. Subjects were recruited in the current study if they reported their residential addresses where they lived during the past 12 months and the address could be validated through Hong Kong GeoInfo Map. Subjects were excluded if any of the following criteria was met: (1) reported moving twice, each of which happened during one of the two follow-up rounds; (2) contact lost due to unreachable address during the first follow-up; (3) too frail to approach the study site since the first follow-up and (4) the coverage of green space was extremely high $(\geq 100 \%)$. Therefore, subjects included in the study had lived at the stated address for at least 3 years so that their exposure to the neighbouring green space was deemed to be stable. Figure 1 shows the recruitment flow. The study was approved by the Clinical Research Ethics Committee of the Chinese University of Hong Kong, and the written informed consent was obtained from all subjects.

\section{Assessment of green space}

The Normalised Difference Vegetation Index (NDVI) was used as the indicator for green spaces. It was calculated as the ratio of the difference between the near-infrared and red region to the sum of them, indicating the quantity and variation of the live vegetation contained in the observed target site. ${ }^{33}$ NDVI has been validated by experts as a useful measure of neighbourhood coverage of green space. ${ }^{34} \mathrm{~A}$ vegetation map was created with ArcGIS 10.3, based on reclassifying a $15 \mathrm{~m}$ NDVI map ${ }^{35}$ that was derived from IKONOS multispectral images, with the map displayed as pixels $\left(15^{*} 15 \mathrm{~m}\right)$ to which each pixel was identified as green space when the NDVI is larger than $0.1 .{ }^{34}$ Therefore, with the coordinates of each individual address obtained at baseline through the Hong Kong GeoInfo Map as the centre of study unit, the $\%$ of green space within a particular buffer zone of the subject's address was calculated by counting the number of green pixels. Since there is no consensus on the optimum green space buffer for a health effect in older people, a buffer zone of $300 \mathrm{~m}$ (approximately 5-min walking distance for older Chinese people with an average walking speed of approximately $1.0 \mathrm{~m} / \mathrm{s})^{36}$ was used in this study to capture the coverage of green space, a distance shown from previous studies to be appropriate. ${ }^{37-40}$ In addition, according to the Hong Kong Planning Standards and Guidelines, local open spaces (including green spaces) should be located within short walking distance from the residents 


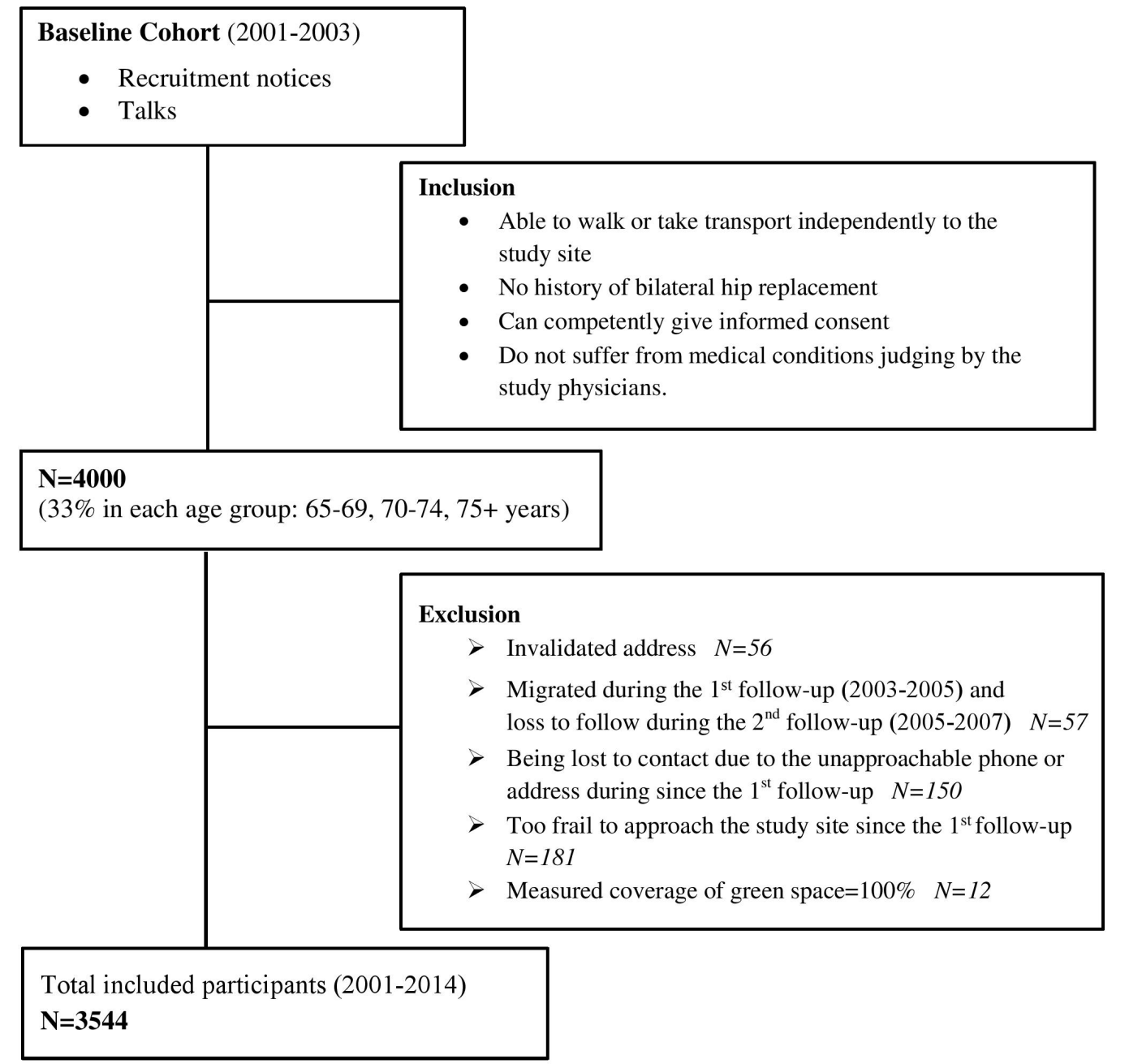

Figure 1 Flow chart of recruitment at baseline (2001-2004).

it intends to serve, preferably within a radius of not more than about $400 \mathrm{~m}^{41}$

\section{Mortality ascertainment}

Mortality data were ascertained by the Government Death Registry through 31 March 2014. Causes of death were coded based on the 10th revision of the International classification of diseases (ICD-10) ${ }^{42}$ Mortality attributable to respiratory system disease and circulatory system disease, including ischaemic heart disease (IHD), acute myocardial infarction(AMI) and stroke were extracted specifically due to their high prevalence among the older population and previous studies suggesting their significant correlation with green space. ${ }^{14}$

\section{Covariate}

Questionnaires covering demographics, socioeconomics, lifestyle and health conditions were administered by a team of trained research assistants at baseline. Demographics included age, sex, marital status and years lived in Hong Kong. Education level (not educated, primary school-not completed, primary school-graduate, secondary school, university or above) was obtained as a proxy of objective socioeconomic status. Subjective socioeconomic status was measured using the self-reported social economic status ladder proposed by Adler and Ostrove $^{43}$ that takes the psychological dimension into account. The version we used is validated for the context of Hong Kong. It consists of ten rungs, with the top rung indicating people with the most satisfied income, education level and job respect, while the bottom rung representing the opposite extreme. ${ }^{44}{ }^{45}$ Lifestyle factors included smoking (non-smoker, past-smoker, currentsmoker), alcohol intake (intake greater than 12 drinks during the past 12 months or not) and the dietary quality being assessed by the Diet Quality Index-International (DQI-I) ${ }^{46}$ Physical activity levels were also evaluated using the Physical Activity Scale for the Elderly (PASE). The questionnaire consists of 12 items conveying occupational, household and leisure activities during a 1-week period, with a higher summary score representing a higher daily physical activity level. Health conditions including cognitive function, general mental health and self-rated health were estimated. The mini-mental state examination (MMSE) was used to measure cognitive function. The maximum score is 30 , while a score below 24 indicates mild (19-23), moderate (10-18) or severe ( $\leq 9)$ cognitive impairment. ${ }^{47}$ The Short Form-12 (SF-12) 
Mental Component Summary (MCS) was used to evaluate the general mental health status, ${ }^{48}$ with a range from 0 to 100 , a higher score indicating a better mental health component of health-related quality of life. Self-rated overall health status was assessed by asking a question 'How would you rate your overall health?' with five options ranging from 'very good' to 'poor'.

Environmental factors regarding housing type, air pollution, highway proximity, building density and living height, which are potential confounding factors in the relationship between green space and mortality, were also obtained. The housing type was classified as public or private according to the Hong Kong Housing Authority (2016). The mean annual PM2.5 concentration $\left(\mu \mathrm{g} / \mathrm{m}^{3}\right)$ based on the individual address was estimated using remote satellite data at a resolution of $1 \mathrm{~km} .{ }^{49}$ Road network map was obtained from the Hong Kong Planning Department and highway proximity was measured in metres $(\mathrm{m})$ from the residential address to the closest highway as an indicator of traffic-caused noise and air pollution..$^{50}$ Building shape files, containing geocoded information and the shape and height of all buildings in Hong Kong, were acquired from the Hong Kong Planning Department. They were imported into the ArcGIS platform and converted to the raster format for subsequent calculation. Building density was calculated from the percentage of ground covered by buildings (ie, ground coverage) based on the size of buffer employed. In addition, digital elevation model was acquired from the Hong Kong Lands Department for calculating the absolute living height according to the topographic height and the number of storeys in order to compare the environments surrounding the subjects' addresses.

\section{Statistical analysis}

Continuous variables were summarised as mean (SD) or median (IQR), whereas categorical variables by counts and percentages. One-way analysis of variance (ANOVA) was conducted to examine the difference of green space (ie, coverage of green space) and follow-up duration in terms of each characteristic of the subjects. For those characteristics where no significant difference between groups was found, they were excluded in the subsequent models. Spearman's correlation coefficients were also calculated to estimate the correlations of neighbouring green space with years lived in Hong Kong, DQI-I, PASE, MMSE, MCS, highway proximity, PM2.5, average building density and absolute living height. A martingale residual plot was obtained to check whether there was a linear trend between greenery coverage and the log hazard of mortality. Since tests of linearity did not show evidence of a non-linear relationship with mortality, coverage of green space was considered as a continuous variable in the subsequent analyses. Cox proportional hazard models were used to estimate HR and their 95\% CI of every $10 \%$ increase in coverage of green space for all-cause, respiratory system disease, circulatory system disease, IHD or AMI and stroke-caused mortality during the follow-up period (the time from the baseline examination to the date of death). Two models (Model 1 and Model 2) were performed. Model 1 (ie, the primary model) included demographics (age, sex, marital status, years lived in Hong Kong), socioeconomics (education level, socioeconomic ladder), lifestyle factors (smoking, alcohol intake, diet quality), self-rated health and housing type. Model 2 contained covariates in Model 1, PASE and MMSE. PASE and MMSE were selected in Model 2 as these parameters were considered as potential factors linking green space and health. ${ }^{51}{ }^{52}$ MCS, highway proximity and PM2.5 were not included in the model because they were not associated with mortality. Average building density and absolute living height were also not included due to their collinearity with green space. Subgroup analysis was also conducted to compare the effect of green space on mortality by sex. All of the statistical analyses were performed using the SPSS Statistics version 22.0 (IBM, Released 2013, Armonk, New York, USA), with the significance level of $p<0.05$. Missing values were imputed using the average level of the cohort. The study was reported following the STROBE guidelines for reporting observational studies (see online supplementary material 1 ).

\section{RESULTS}

Table 1 shows the number of deaths from all-cause and cause-specific mortality. During a mean follow-up of 10.3 $(\mathrm{SD}=2.3)$ years, 785 deaths from all-cause were identified. The three leading causes were neoplasms (39.4\%), diseases of the circulatory system $(22.9 \%)$ and respiratory system $(18.9 \%)$. Specifically, within the circulatory system diseases, $9.4 \%$ of 795 deaths were caused by either IHD or AMI and $6.2 \%$ were caused by stroke.

Table 2 describes the cohort characteristics in terms of median follow-up duration and the coverage of green space. One-half of the subjects were male, with an overall average age of $72.2(\mathrm{SD}=5.0)$ years and a median coverage of green space of $13.4 \%(\mathrm{IQR}=29.1)$. Subjects who were younger, married, drank more than 12 drinks during the past 12 months, with better self-rated health and higher education level were more likely to continue follow-up for a longer period (all $\mathrm{p}$ values $<0.05$ ). On the other hand, those who ranked lowest (1-3) or highest (7-10) on the socioeconomic ladder and were less educated were more likely to live in areas of higher coverage of green space (all $\mathrm{p}$ values $<0.05$ ).

Table 3 shows the HR (95\% CI) obtained from the primary model (Model 1) and an additional model (Model 2) adding PASE and MMSE. In Model 1, every $10 \%$ increase in coverage of green space was significantly associated with a reduced risk of all-cause mortality (HR $0.96,95 \%$ CI 0.930 to $0.998, p=0.04)$, circulatory system disease-caused mortality (HR 0.88 , 95\% CI 0.81 to 0.96 , $\mathrm{p}=0.004$ ) and stroke-caused mortality (HR 0.66, 95\% CI 0.52 to $0.83, \mathrm{p}=0.001$ ), after adjustments for age, sex, marital status, years lived in Hong Kong, education level, socioeconomic ladder, smoking, alcohol intake, diet 
Table 1 Number of deaths according to specific causes of death and the corresponding percentage divided by all-cause deaths for the cohort of 3544 elderly subjects, Hong Kong, 2001-2014

\begin{tabular}{|c|c|c|c|c|}
\hline Cause & ICD-10 & $\begin{array}{l}\text { All subjects } \\
n=3544\end{array}$ & $\begin{array}{l}\text { Males } \\
n=1773\end{array}$ & $\begin{array}{l}\text { Females } \\
n=1771\end{array}$ \\
\hline All causes & All & $795(22.4 \%)^{*}$ & $515(29.0 \%)^{*}$ & $280(15.8 \%)^{\star}$ \\
\hline $\begin{array}{l}\text { Diseases of the } \\
\text { respiratory system }\end{array}$ & J00-J99 & $150(18.9 \%)$ & $105(20.3 \%)$ & $45(16.0 \%)$ \\
\hline IHD/AMI-caused & $1219,249,251,259$ & $75(9.4 \%)$ & $46(8.9 \%)$ & $27(9.6 \%)$ \\
\hline Stroke-caused & $164,609,613-615,619,620,629,634,639$ & $49(6.2 \%)$ & $30(5.8 \%)$ & $19(6.7 \%)$ \\
\hline
\end{tabular}

*Number of all-cause mortality (mortality ratio), among all subjects, males and females.

AMI, acute myocardial infarction; ICD, International classification of diseases; IHD, ischaemic heart disease.

quality, self-rated health and housing type. No significant association was observed between coverage of green space and respiratory disease-caused mortality or AMI/IHD-caused mortality. However, the inverse associations between coverage of green space with all-cause mortality (HR $0.964,95 \%$ CI 0.931 to 0.999 ) and circulatory system disease-caused mortality (HR 0.888, 95\% CI 0.817 to 0.964 ) were attenuated after further adjustments for PASE and MMSE.

Significant gender differences were observed in the association between coverage of green space and cause-specific mortality (figure 2). Coverage of green space was significantly associated with a reduced risk of all-cause mortality in women (HR $0.93,95 \%$ CI 0.88 to 0.99 ), but not in men (HR $0.97,95 \%$ CI 0.93 to 1.01 ). The association between coverage of green space and circulatory system-caused mortality was stronger in women (HR $0.85,95 \%$ CI 0.74 to 0.97 ) than in men (HR $0.89,95 \%$ CI 0.81 to 0.99 ). However, the association between coverage of green space and stroke-caused mortality was stronger in men (HR $0.59,95 \%$ CI 0.41 to 0.84 ) than in women (HR $0.71,95 \%$ CI 0.52 to 0.96$)$.

\section{DISCUSSION}

Our results show that older people who live in a greener neighbourhood may have a lower risk of all-cause mortality, particularly for mortality caused by circulatory diseases, including stroke, independent of age, sex, marital status, years lived in Hong Kong, education level, socioeconomic ladder, smoking, alcohol intake, diet quality, self-rated health and housing type. The inverse association between green space and mortality persisted after further adjustments for physical activity and cognitive function, which have been suggested as important factors linking green space to improved health and well-being. ${ }^{53-57}$

The findings of this study are consistent with the findings reported in other studies which also used NDVI to assess the neighbouring coverage of green space for adults. ${ }^{14} 15$ In particular, a cohort study conducted in Japan found a similar positive association between walkable green space and longevity for senior citizens. ${ }^{13}$ However, while the comparison with other studies confirms the beneficial effect of green space on mortality, most previous studies collected the reported residential address only once at baseline, assuming stable exposure to green space, which may not be true, especially in cities, with a high rate of residence change or if the individually reported address is not the predominant living place of the subject. Unlike other studies, we established certain recruiting criteria to ensure that all of the subjects had an exposure to their neighbouring green space for a period longer than 3 years.

Although coverage of green space was associated with a reduced risk of all-cause mortality and mortality caused by stroke in the present study, it was not associated with respiratory system disease-caused or AMI/IHD-caused mortality. The lack of an association between green space and respiratory system-caused mortality may be due to the lack of variation in exposure to green space in subjects who had died of respiratory diseases. In addition, the vulnerability of the respiratory system of those subjects may have limited their daily activities or changed their health behaviours such that the connection with the neighbouring green space may have been of less benefit. ${ }^{58}$ In terms of AMI/IHD-caused mortality, the lack of an association may be due to the relatively small number of deaths caused by AMI/IHD in the study.

Our findings also showed that the effect of green space on all-cause mortality tended to be stronger in females than in males. The observed stronger association for females may be related to the relatively greater exposure to the neighbouring green space (eg, visit the residential market, participate in community activities), as observed from other studies. ${ }^{59-61}$ Nevertheless, the number of deaths caused by AMI/IHD and stroke in the study were small. A longer follow-up period with a larger number of deaths from AMI/IHD and stroke might be able to provide a more definitive answer. Further studies exploring the health effect of neighbouring environment should also take gender difference into account 
Table 2 Descriptive characteristics of the study population and percentage of green space coverage within neighbouring buffer (radius $=300 \mathrm{~m})$ at baseline $(n=3544)$

\begin{tabular}{|c|c|c|c|c|c|c|}
\hline & \multicolumn{2}{|c|}{ Number of subjects } & \multicolumn{2}{|c|}{ Total months of follow-up } & \multicolumn{2}{|c|}{$\begin{array}{l}\text { Coverage of green space } \\
(\%)\end{array}$} \\
\hline & N (\%) & $\begin{array}{l}\text { Median } \\
\text { (IQR) }\end{array}$ & $\begin{array}{l}\text { Median } \\
\text { (IQR) }\end{array}$ & $\begin{array}{l}\text { Correlation } \\
\text { coefficient }\end{array}$ & $\begin{array}{l}\text { Median } \\
\text { (IQR) }\end{array}$ & $\begin{array}{l}\text { Correlation } \\
\text { coefficient }\end{array}$ \\
\hline Overall subjects & $3544(100 \%)$ & & $133.32(14.2)$ & & $13.36(29.1)$ & \\
\hline \multicolumn{7}{|l|}{ Demographics } \\
\hline \multicolumn{7}{|l|}{ Sex } \\
\hline Male & $1773(50.0)$ & & $137.2(13.9)$ & & $12.25(29.1)$ & \\
\hline Female & $1771(49.9)$ & & $128.4(9.2)$ & & $14.16(29.9)$ & \\
\hline Age (years) & & $72.2(5.0)$ & & -0.25 & & 0.01 \\
\hline 65-70 & $1550(43.8)$ & & $135.0(13.8)^{*}$ & & $13.13(28.7)$ & \\
\hline $71-75$ & $1111(31.4)$ & & $134.0(13.0)$ & & $13.21(30.1)$ & \\
\hline $76-80$ & $654(18.4)$ & & $127.7(26.3)$ & & $13.64(31.1)$ & \\
\hline $81-85$ & $181(5.1)$ & & $122.5(51.3)$ & & $13.13(28.7)$ & \\
\hline$\geq 86$ & $48(1.3)$ & & $110.6(53.1)$ & & $17.58(35.0)$ & \\
\hline \multicolumn{7}{|l|}{ Marital status } \\
\hline Married & 2546 (71.9) & & $135.3(13.9)^{\star}$ & & $12.85(29.2)$ & \\
\hline Widowed & $849(23.9)$ & & $127.5(8.0)$ & & $14.16(29.0)$ & \\
\hline Separated or divorced & $79(2.2)$ & & $128.7(16.7)$ & & $16.63(37.7)$ & \\
\hline Single (never married) & $70(2.0)$ & & $126.9(48.9)$ & & $16.23(30.7)$ & \\
\hline Years lived in Hong Kong & & $52.7(14.9)$ & & $-0.05^{*}$ & & -0.02 \\
\hline \multicolumn{7}{|l|}{ Socioeconomics } \\
\hline \multicolumn{7}{|l|}{ Education Level } \\
\hline Not educated & $743(20.9)$ & & $128.4(10.2)^{\star}$ & & $16.07(28.6)$ & \\
\hline Primary school not completed & $1164(32.8)$ & & $132.8(14.2)$ & & $13.60(31.2)$ & \\
\hline Primary school graduated & $606(17.2)$ & & $134.0(14.9)$ & & $12.93(31.9)$ & \\
\hline Secondary school & $679(17.1)$ & & $135.8(14.6)$ & & $11.46(25.5)$ & \\
\hline University or above & $352(9.9)$ & & $135.8(12.4)$ & & $9.11(23.8)$ & \\
\hline \multicolumn{7}{|l|}{ Socioeconomic ladder } \\
\hline Low (1-3) & $973(27.4)$ & & $134.4(16.1)$ & & $13.37(30.3) \dagger$ & \\
\hline Medium (4-6) & $2142(60.5)$ & & $132.9(13.7)$ & & $13.13(29.2)$ & \\
\hline High (7-10) & $429(12.1)$ & & $133.4(12.3)$ & & $13.37(27.5)$ & \\
\hline \multicolumn{7}{|l|}{ Lifestyle factors } \\
\hline \multicolumn{7}{|l|}{ Smoking } \\
\hline Non-smoker & $2259(63.8)$ & & $127.7(11.8)^{\star}$ & & $13.29(28.5)$ & \\
\hline Past-smoker & $1046(29.5)$ & & $136.0(24.3)$ & & $13.37(30.6)$ & \\
\hline Current-smoker & $239(6.7)$ & & $135.4(23.4)$ & & $14.16(32.6)$ & \\
\hline \multicolumn{7}{|l|}{ Alcohol intake } \\
\hline $\begin{array}{l}\text { Intake } \leq 12 \text { drinks during the } \\
\text { past } 12 \text { months }\end{array}$ & 3069 (86.6) & & $132.6(13.6) \dagger$ & & $13.37(29.3)$ & \\
\hline $\begin{array}{l}\text { Intake }>12 \text { drinks during the } \\
\text { past } 12 \text { months }\end{array}$ & $475(13.4)$ & & $137.2(10.6)$ & & $12.41(27.2)$ & \\
\hline DQI-I & & $64.45(9.5)$ & & $0.08^{\star}$ & & $-0.03 \dagger$ \\
\hline PASE & & $91.9(43.0)$ & & 0.14 & & 0.01 \\
\hline \multicolumn{7}{|l|}{ Health conditions } \\
\hline MMSE & & 25.7 (3.6) & & $0.11^{\star}$ & & -0.13 \\
\hline
\end{tabular}

Continued 
Table 2 Continued

\begin{tabular}{|c|c|c|c|c|c|c|}
\hline & \multicolumn{2}{|c|}{ Number of subjects } & \multicolumn{2}{|c|}{ Total months of follow-up } & \multicolumn{2}{|c|}{$\begin{array}{l}\text { Coverage of green space } \\
(\%)\end{array}$} \\
\hline & $\mathrm{N}(\%)$ & $\begin{array}{l}\text { Median } \\
\text { (IQR) }\end{array}$ & $\begin{array}{l}\text { Median } \\
\text { (IQR) }\end{array}$ & $\begin{array}{l}\text { Correlation } \\
\text { coefficient }\end{array}$ & $\begin{array}{l}\text { Median } \\
\text { (IQR) }\end{array}$ & $\begin{array}{l}\text { Correlation } \\
\text { coefficient }\end{array}$ \\
\hline MCS & & $55.5(7.2)$ & & -0.01 & & 0.01 \\
\hline \multicolumn{7}{|l|}{ Self-rated health } \\
\hline Very good & $335(9.5)$ & & $136.0(14.5)^{\star}$ & & $12.65(29.8)$ & \\
\hline Good & $1354(38.2)$ & & $134.2(14.3)$ & & $12.65(29.0)$ & \\
\hline Fair & $1607(45.3)$ & & $131.5(13.3)$ & & $14.48(29.6)$ & \\
\hline Substandard & $220(6.2)$ & & $128.7(12.3)$ & & $12.29(26.7)$ & \\
\hline Poor & $28(0.8)$ & & $127.2(37.1)$ & & $15.16(31.6)$ & \\
\hline \multicolumn{7}{|l|}{ Environmental factors } \\
\hline \multicolumn{7}{|l|}{ Housing type } \\
\hline Private housing & $1521(42.9)$ & & $134.2(13.5)$ & & $12.65(29.4)$ & \\
\hline Public housing & $2023(57.1)$ & & $132.6(14.8)$ & & $13.68(29.7)$ & \\
\hline Highway proximity $(\mathrm{m})$ & & $138.9(202.1)$ & & -0.01 & & $0.16^{\star}$ \\
\hline PM2.5 concentration $\left(\mu \mathrm{g} / \mathrm{m}^{3}\right)$ & & $32.4(2.6)$ & & $-0.04 \dagger$ & & $-0.45^{*}$ \\
\hline Average building density (\%) & & $34.8(9.8)$ & & 0.01 & & $-0.65^{\star}$ \\
\hline Absolute living height (m) & & $112.9(88.2)$ & & -0.01 & & $0.46^{\star}$ \\
\hline
\end{tabular}

For categorical characteristics, the number of subjects $\mathrm{n}$ (\% divided by the total $\mathrm{N}$ ), the average follow-up duration and coverage of green space for each category are shown as median (IQR). For continuous variables, the average level of continuous variables for all subjects is presented as mean (SD) or median (IQR) if non-normal distribution was observed; their correlation with follow-up duration or coverage of green space is reported using Spearman's correlation coefficient.

${ }^{*}$ Difference between groups or correlation with a continuous variable is significant at the 0.01 level (two-tailed).

†Difference between groups or correlation with a continuous variable is significant at the 0.05 level (two-tailed).

DQI, Diet Quality Index-International; MCS, The mental component of SF-12; MMSE, Mini-Mental State Examination; PASE, Physical Activity Scale for the Elderly.

Table 3 Multivariate-adjusted HRs and $95 \%$ Cls of all-cause and cause-specific mortality with every $10 \%$ increase in coverage of green space within a $300 \mathrm{~m}$ radius buffer

HR (95\% Cl), adjusted for demographic, socioeconomic, lifestyle factors, baseline health status, housing type and years lived in HK

Outcomes Model $1^{\star}$ Model $^{2 \dagger}$

\begin{tabular}{lll} 
Outcomes & Model $1^{\star}$ & Model $^{2 \dagger}$ \\
\hline All-cause mortality & Green space $(10 \%)$ & Green space (10\%) \\
\hline Respiratory disease-caused mortality & $0.963(0.930 \text { to } 0.998)^{\ddagger}$ & $0.964(0.931 \text { to } 0.999)^{\ddagger}$ \\
\hline Circulatory disease-caused mortality & $0.003(0.927$ to 1.086$)$ & $1.004(0.928$ to 1.087$)$ \\
\hline IHD/AMI & $0.912(0.805$ to 1.033$)$ & $0.888(0.817 \text { to } 0.964)^{\S}$ \\
\hline Stroke & $0.661(0.524 \text { to } 0.835)^{\S}$ & $0.912(0.805$ to 1.033$)$ \\
\hline
\end{tabular}

HR by Cox proportional regression with specific mortality as the dependent variable; coverage of green space is the primary independent variable.

* Model 1 was established to evaluate the overall effect of green space, controlling for demographic factors(age, sex, marital status, years lived in Hong Kong), socioeconomics(education level, subjective social economic status ladder), lifestyle factors(smoking, alcohol intake, diet quality), baseline health status and housing type

†Model 2 was developed based on the basic model, with PASE and MMSE added.

$\ddagger$ Significant at the 0.05 level (two-tailed).

$\S$ Significant at the 0.01 level (two-tailed).

AMI, acute myocardial infarction; IHD, ischaemic heart disease; MMSE, Mini-Mental State Examination; PASE, Physical Activity Scale for the Elderly. 


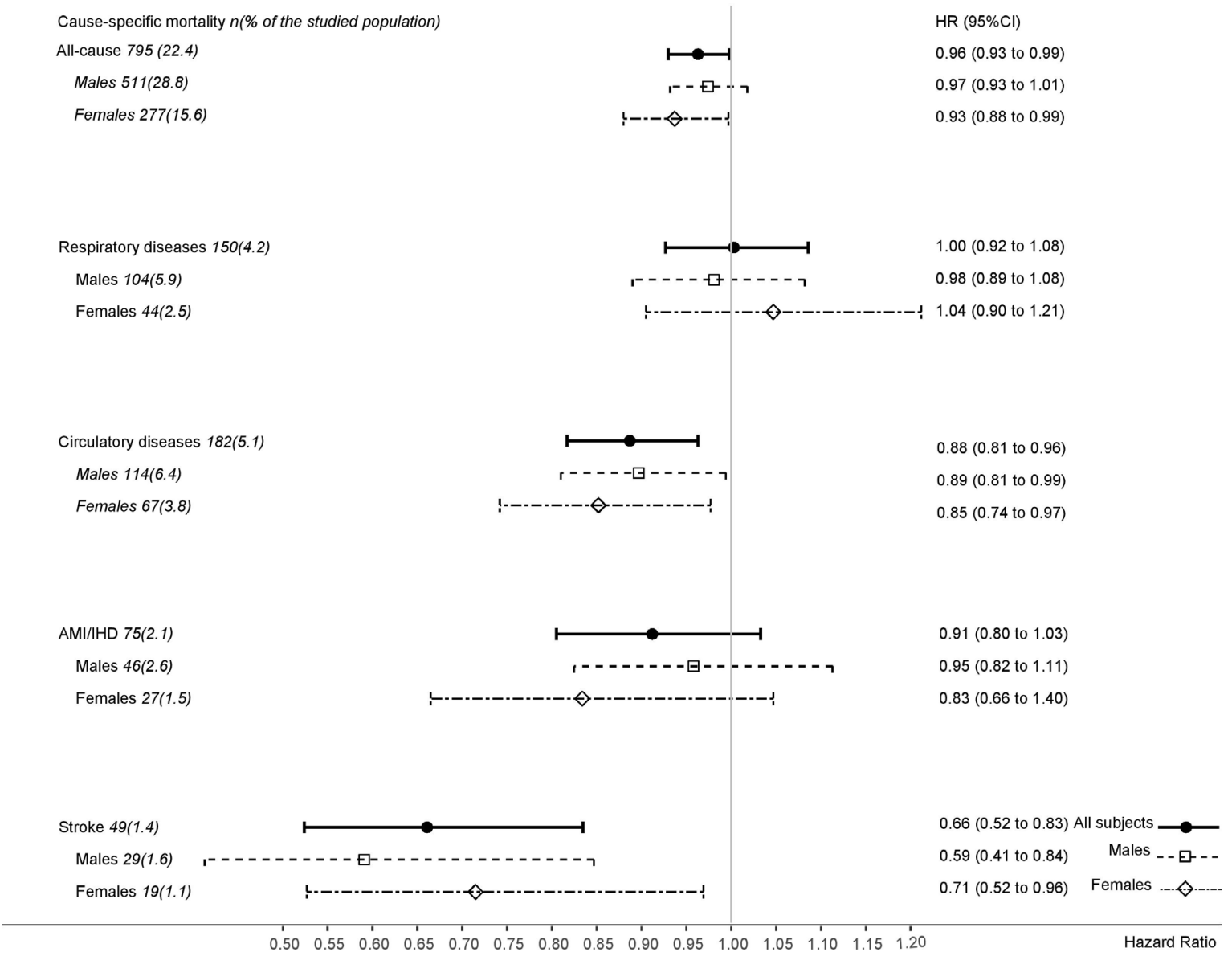

Figure 2 Multivariate-adjusted HRs and 95\% Cls of all-cause, respiratory system, circulatory system, ischaemic heart disease (IDH) or acute myocardial infarction (AMI) and stroke-caused mortality with every $10 \%$ increase in coverage of green space within a $300 \mathrm{~m}$ radius buffer.

to provide applicable evidence for urban planners in addressing various needs from different populations.

The present study has several limitations. First, the number of deaths from AMI/IHD and stroke were small. Second, green space was derived from NDVI, which does not necessary reflect the access to green spaces. Nevertheless, coverage of green space was used, which has been suggested as an indicator to capture the beneficial effects of green space within a walking-reachable distance for the old population which may be also relevant to health. ${ }^{37}$ Third, although air pollution has been suggested as an important factor linking green space and health, ${ }^{4}$ indicators of pollution such as PM2.5 and highway proximity collected in this study were not associated with mortality and therefore were not included in the models. The lack of statistical significance may be explained by the inadequate measurement precision of PM2.5 (with a resolution of $1 \mathrm{~km}$ ) and the indirect measurement of traffic-caused pollution. Nevertheless, the strengths of this study lie in the longitudinal design, the use of an accurate method to measure green space on the individual level, the adjustment for multiple potential confounders as well as physical activity level and cognitive function, which are known to influence risk of mortality and the adequate representativeness of the current cohort in terms of health aspect, because the leading causes of mortality in the current study are in line with the general mortality pattern in Hong Kong, where neoplasms, diseases of the circulatory system and diseases of the respiratory system contributed the majority of mortality from 2001 to $2015 .^{62}$

In conclusion, our findings suggest that living in a neighbourhood with higher coverage of green space could be a promising means of attenuating risks for all-cause and circulatory diseases-caused mortality in older Chinese people living in a highly urbanised city. The beneficial effects were independent of demographics, socioeconomics, lifestyle, self-rated health, housing type as well as physical activity and cognitive function, suggesting that other potential pathways relating to air quality, ${ }^{63}$ temperature, ${ }^{64}$ social cohesion ${ }^{65}$ and psychological state,${ }^{66}$ should be studied to understand the relationship between exposure to green space and mortality. Our study provides useful information for urban planning and improving population health. Further studies with larger sample size and prospective design are required to confirm these associations and to explore underlying pathways that might contribute to the beneficial effect of green space on health. 
Acknowledgements The authors are grateful to Dr Edith Lau who set up the elderly cohort and thankful to Mr Jason Leung and Ms Blanche Yu from the Jockey Club Center for Osteoporosis Care and Control of The Chinese University of Hong Kong for their help in data management in this study, Professor LAO Xiangqian who contributed to the measurement of air pollutants, Hung Chak Ho who helped with measuring the green space and proximity to highway. The authors also would like to thank all the subjects for their dedicated contribution to the study.

Contributors JW and TTYK led the establishment and follow-ups of the studied cohort in collaboration with RY and SYSW. DW designed the specific study, collected data and conducted the analysis in collaboration with KK-LL. DW prepared the raw draft of this manuscript, with all authors contributing to its main content and critically revising it. All authors declare they have approved this manuscript to submit.

Funding We declare that there is no fund for the present study.

Competing interests None declared.

Patient consent Obtained.

Ethics approval Clinical Research Ethics Committee of the Chinese University of Hong Kong.

Provenance and peer review Not commissioned; externally peer reviewed. Data sharing statement None.

Open Access This is an Open Access article distributed in accordance with the Creative Commons Attribution Non Commercial (CC BY-NC 4.0) license, which permits others to distribute, remix, adapt, build upon this work non-commercially, and license their derivative works on different terms, provided the original work is properly cited and the use is non-commercial. See: http://creativecommons.org/ licenses/by-nc/4.0/

(c) Article author(s) (or their employer(s) unless otherwise stated in the text of the article) 2017. All rights reserved. No commercial use is permitted unless otherwise expressly granted.

\section{REFERENCES}

1. Tzoulas K, Korpela K, Venn S, et al. Promoting ecosystem and human health in urban areas using green infrastructure: A literature review. Landsc Urban Plan 2007;81:167-78.

2. Dunnett N, ed. Improving Urban Parks, Play Areas and green spaces. Great Britain: Department of Landscape, University of Sheffield, 2002.

3. Kuo FE. Journal of Arboriculture. Social Aspects of Urban Forestry: the Role of Arboriculture in a Healthy Social Ecology 2003;29.

4. Zupancic T. The impact of green space on heat and air pollution in urban communities: A meta-narrative systematic review. Westmacott C, ed. Mike Bulthuis, 2015.

5. Grimm NB, Faeth SH, Golubiewski NE, et al. Global change and the ecology of cities. Science 2008;319:756-60.

6. van den Berg M, Wendel-Vos W, van Poppel M, et al. Health benefits of green spaces in the living environment: a systematic review of epidemiological studies. Urban For Urban Green 2015;14:806-16.

7. WLC-i-P D, ed. Global age-friendly cities: a guide: France, 2007.

8. Fried LP, Tangen CM, Walston J, et al. Cardiovascular Health Study Collaborative Research Group. Frailty in older adults: evidence for a phenotype. J Gerontol A Biol Sci Med Sci 2001;56:M146-M157.

9. Hong YC. Aging society and environmental health challenges. Environ Health Perspect 2013;121:a68-a69.

10. Wiles JL, Leibing A, Guberman N, et al. The meaning of "aging in place" to older people. Gerontologist 2012;52:357-66.

11. Ago Y. High-Density Living. Kong H, Lsecities, 2011.

12. United Nations Department of Economic and Social Affairs. "United Nations World Population Prospects: 2015 revision. UN.

13. Takano T, Nakamura KFau-Watanabe M, Watanabe M. The importance of walkable green spacesUrban residential environments and senior citizens' longevity in megacity areas, 2002. (0143-005X (Print)).

14. Gascon M, Triguero-Mas M, Martínez D, et al. Residential green spaces and mortality: A systematic review. Environ Int 2016;86:60-7.

15. Villeneuve PJ, Jerrett M, Su JG, et al. A cohort study relating urban green space with mortality in Ontario, Canada. Environ Res 2012;115:51-8.

16. Richardson EA, Mitchell R. Gender differences in relationships between urban green space and health in the United Kingdom. Soc Sci Med 2010;71:568-75.
17. Tamosiunas A, Grazuleviciene R, Luksiene D, et al. Accessibility and use of urban green spaces, and cardiovascular health: findings from a Kaunas cohort study. Environ Health 2014;13:11-13.

18. van den Berg AE, Maas J, Verheij RA, et al. Green space as a buffer between stressful life events and health. Soc Sci Med 2010;70:1203-10.

19. Sugiyama T, Leslie E, Giles-Corti B, et al. Associations of neighbourhood greenness with physical and mental health: do walking social coherence and local social interaction explain the relationships? Journal of Epidemiology and Community Health 2008;62:e9.

20. Lee IM, Rexrode KM, Cook NR, et al. Physical activity and coronary heart disease in women: is "no pain, no gain" passé? JAMA 2001;285:1447-54.

21. Shaw KA, Gennat HC, O'Rourke P, et al. Exercise for overweight or obesity. The Cochrane Library 2006.

22. Thomas D, Elliott EJ, Naughton GA. Exercise for type 2 diabetes mellitus. Cochrane Database Syst Rev 2006;3.

23. Gregg EW, Pereira MA, Caspersen CJ. Physical activity, falls, and fractures among older adults: a review of the epidemiologic evidence. J Am Geriatr Soc 2000;48:883-93.

24. Coombes E, Jones AP, Hillsdon M. The relationship of physical activity and overweight to objectively measured green space accessibility and use. Soc Sci Med 2010;70:816-22.

25. Cohen DA, Ashwood JS, Scott MM, et al. Public parks and physical activity among adolescent girls. Pediatrics 2006;118:e1381-e1389.

26. Kahn EB, Ramsey LT, Brownson RC, et al. The effectiveness of interventions to increase physical activity. A systematic review. Am J Prev Med 2002;22(4 Suppl):73-107.

27. Lachowycz K, Jones AP. Greenspace and obesity: a systematic review of the evidence. Obes Rev 2011;12:e183-e189.

28. Wilker EH, Wu CD, McNeely E, et al. Green space and mortality following ischemic stroke. Environ Res 2014;133:42-8.

29. Richardson E, Pearce J, Mitchell R, et al. The association between green space and cause-specific mortality in urban New Zealand: an ecological analysis of green space utility. BMC Public Health 2010;10:1.

30. Richardson EA, Mitchell R, Hartig T, et al. Green cities and health: a question of scale? J Epidemiol Community Health 2012;66:160-5.

31. Liu B, Woo J, Tang N, et al. Assessment of total energy expenditure in a chinese population by a physical activity questionnaire: examination of validity. Int J Food Sci Nutr 2001;52:269-82.

32. Kwok T, Khoo CC, Leung J, et al. Predictive values of calcaneal quantitative ultrasound and dual energy $X$ ray absorptiometry for non-vertebral fracture in older men: results from the MrOS study (Hong Kong). Osteoporos Int 2012;23:1001-6.

33. Rouse JW, Haas RH, Schell JA, et al. Monitoring Vegetation Systems in the great plains with ERTS, 1973.

34. Rhew IC, Vander Stoep A, Kearney A, et al. Validation of the normalized difference vegetation index as a measure of neighborhood greenness. Ann Epidemiol 2011;21:946-52.

35. Nichol J, Wong MS, Fung C, et al. Assessment of Urban Environmental Quality in a Subtropical City using Multispectral Satellite Images. Environment and Planning B: Planning and Design 2006;33:39-58.

36. Yu R, Leung J, Woo J. Incremental predictive value of sarcopenia for incident fracture in an elderly chinese cohort: results from the osteoporotic fractures in men (MrOs) Study. J Am Med Dir Assoc 2014;15:551-8.

37. Grahn P, Stigsdotter UA. Landscape planning and stress. Urban For Urban Green 2003;2:1-18.

38. Nielsen TS, Hansen KB. Do green areas affect health? Results from a danish survey on the use of green areas and health indicators. Health Place 2007;13:839-50.

39. Annerstedt M, Ostergren PO, Björk J, et al. Green qualities in the neighbourhood and mental health - results from a longitudinal cohort study in Southern Sweden. BMC Public Health 2012;12:337.

40. Björk J, Albin M, Grahn P, et al. Recreational values of the natural environment in relation to neighbourhood satisfaction, physical activity, obesity and wellbeing. J Epidemiol Community Health 2008;62:e2

41. Department $P$, ed. Planning and urban design for a liveable highdensity city, 2016:25-6.

42. Organization WH. International statistical classification of diseases and related health problems: World Health Organization, 2004.

43. Adler NE, Ostrove JM. Socioeconomic status and health: what we know and what we don't. Ann N Y Acad Sci 1999;896:3-15.

44. Woo J, Leung J Fau-Chan R, Chan R Fau-Chau PH, et al. Influence of income and self-rated socio-economic position on lifestyle, and physical and psychological function in older Chinese adults aged 65 years and over, 2013. 
45. Woo J, Lynn H, Leung J, et al. Self-perceived social status and health in older Hong Kong Chinese women compared with men. Women Health 2008;48:209-34.

46. Kim S, Haines PS, Siega-Riz AM, et al. The Diet Quality IndexInternational (DQI-I) provides an effective tool for cross-national comparison of diet quality as illustrated by China and the United States. J Nutr 2003;133:3476-84.

47. Pangman VC, Sloan J, Guse L. An examination of psychometric properties of the mini-mental state examination and the standardized mini-mental state examination: implications for clinical practice. Appl Nurs Res 2000;13:209-13.

48. Ware J, Kosinski M, Keller SD. A 12-Item Short-Form Health survey: construction of scales and preliminary tests of reliability and validity. Med Care 1996;34:220-33.

49. Lin C, Li Y, Yuan Z, et al. Using satellite remote sensing data to estimate the high-resolution distribution of ground-level PM2.5. Remote Sens Environ 2015;156:117-28.

50. Welch D, Shepherd D, Dirks KN, et al. Road traffic noise and health-related quality of life: a cross-sectional study. Noise Health 2013;15:224-30.

51. Hupin D, Roche F, Gremeaux V, et al. Even a low-dose of moderateto-vigorous physical activity reduces mortality by $22 \%$ in adults aged $\geq 60$ years: a systematic review and meta-analysis. Br J Sports Med 2015;49:1262-7.

52. Parpa E, Tsilika E, Gennimata V, et al. Elderly cancer patients' psychopathology: a systematic review: aging and mental health. Arch Gerontol Geriatr 2015;60:9-15.

53. Booth ML, Owen N, Bauman A, et al. Social-cognitive and perceived environment influences associated with physical activity in older Australians. Prev Med 2000;31:15-22.

54. Guralnik JM, Seeman TE, Tinetti ME, et al. Validation and use of performance measures of functioning in a non-disabled olde population: macarthur studies of successful aging. Aging Clin Exp Res 1994:6:410-9.

55. Taylor AF, Kuo FE, Sullivan WC. Coping with add: the Surprising connection to Green Play Settings. Environ Behav 2001;33:54-77.
56. Hillsdon M, Panter J, Foster C, et al. The relationship between access and quality of urban green space with population physical activity. Public Health 2006;120:1127-32.

57. Maas J, Verheij RA, Spreeuwenberg P, et al. Physical activity as a possible mechanism behind the relationship between green space and health: a multilevel analysis. BMC Public Health 2008;8:1.

58. Cooper CB. Airflow obstruction and exercise. Respir Med 2009;103:325-34.

59. Stafford M, Cummins S, Macintyre S, et al. Gender differences in the associations between health and neighbourhood environment. Soc Sci Med 2005;60:1681-92.

60. Poortinga W, Dunstan FD, Fone DL. Perceptions of the neighbourhood environment and self rated health: a multilevel analysis of the Caerphilly Health and Social needs Study. BMC Public Health 2007;7:285.

61. Kavanagh AM, Bentley R, Turrell G, et al. Does gender modify associations between self rated health and the social and economic characteristics of local environments? J Epidemiol Community Health 2006:60:490-5

62. Census and Statistics Department HKSARThe mortality trend in Hong Kong, 1981 to 2015. Hong Kong: Hong Kong Monthly Digest of Statistics. 2016.

63. Roy S, Byrne J, Pickering C. A systematic quantitative review of urban tree benefits, costs, and assessment methods across cities in different climatic zones. Urban For Urban Green 2012:11:351-63.

64. Bowler DE, Buyung-Ali L, Knight TM, et al. Urban greening to cool towns and cities: a systematic review of the empirical evidence. Landsc Urban Plan 2010;97:147-55.

65. Maas J, van Dillen SM, Verheij RA, et al. Social contacts as a possible mechanism behind the relation between green space and health. Health Place 2009;15:586-95.

66. Nilsson K, Sangster M, Forests KCC. Trees and human health and well-being: introduction. Forests, trees and human health: Springer 2011:1-19. 